\title{
ALMA Y VIDA, EL ORIGEN DE UN FRACASO HISTÓRICO
}

El 9 de abril de 1902 se estrenaba en Madrid Alma y vida de don Benito Pérez Galdós. Es de suponer cierta expectación tras el éxito, y escándalo, de Electra. Pero Alma y vida no logró igualar la obra precedente. Algunos autores hablan de un rotundo fracaso ${ }^{1}$, otros de una buena acogida (Ángel Berenguer, p. 30). Lo cierto es que Galdós, en el prólogo a la edición de la obra, se queja del mal trato que le dio la crítica, aunque sin referirse a la acogida del público, cosa que sí había hecho en el prólogo de Los condenados. Más bien, el autor parece achacar el que su obra pasase bastante desapercibida a la labor descuidada de una crítica mal preparada. Cuáles fueron esas opiniones de los contemporáneos de Galdós acerca de su nueva obra es el primer acercamiento a Alma y vida que debemos hacer.

Lo primero que llama la atención y que señalan casi todos los críticos que presenciaron el estreno, es la calurosa acogida que el público concedió al autor, haciéndole salir al escenario al final de los tres últimos actos. Esto, sin duda, no hace sino manifestar la buena disposición y el interés con que dicho público recibía cada novedad que Pérez Galdós presentaba. Un crítico de la época lo decía así: "¿Quién se libra de la obsesión de Galdós? Es nuestro dictador literario: hay que ser galdosista o antigaldosista forzosamente." (Berenguer, p. 245) ${ }^{2}$

$Y$ es que Galdós era visto como un gran innovador del teatro, de la forma de hacer teatro, levantando opiniones tan entusiastas como la que sigue: "Galdós no es sólo un autor: es 'un teatro'. Apasiona, domina. Gran revolucionario artístico, lucha con la rutina y con la resistencia innata en las muchedumbres contra todo demoledor. También la inmortal labor de Shakespeare tropezó con estas grandes dificultades..." (Berenguer, p. 245).

Pero estas palabras, además de transmitir una gran admiración por el quehacer artístico de Pérez Galdós, dejan translucir otro problema: la incomprensión de un público que iba al teatro, según el propio Galdós, "en busca de emociones fáciles, de ideas claras, de accidentes alegres o patéticos, presentados con arte y brevedad" y sin filosofías. ${ }^{3}$

Sus contemporáneos eran conscientes de que Galdós estaba intentando reformar el teatro y de los problemas que trae no darle al público aquello a lo que está acostumbrado.

1 Isaac Rubio, "Alma y vida, obra fundamental del teatro de Galdós", en: Estudios escénicos, 18/1974, pp. 173-193.

2 Todas las referencias a artículos de la época están tomadas del volumen editado por Ángel Berenguer. Una ampliación de este tipo de bibliografia se puede encontrar en Theodore A. Sackett: Galdós y las máscaras. Instituto di Lingue e Letterature Straniere di Verona, 1982.

3 Benito Pérez Galdós, Los condenados, Obras completas VI. Madrid, Aguilar 1968, p. 700. 
Otro crítico del momento lo ve con lucidez: "el público, aunque resisténdose al principio, con la fuerza de los gustos tradicionalaes, llegará finalmente a aceptar en su plenitud lo que con prodigalidad y constancia ejemplares, le ofrece la inagotable vena del eminente escritor" (Berenguer, p. 244, el subrayado es mío).

Es curioso también observar qué elementos separan a Galdós de los autores teatrales del momento según estos críticos. Por un lado, José de Lara se fija en la calidad artística: "holguémionos de que don Benito siga creyendo que al gran público, y aun al vulgo, se les puede conquistar sin hablarles en necio" (Berenguer, p. 244). Por otro lado, un crítico que firma con el seudónimo de "Caramanchel" se centra en el carácter "humanitario" de su obra literaria, que la hace más "digna de estudio que la de nuestros otros grandes literatos vivos. No busquéis sólo la belleza, sino tambén la intención social, sirviéndole de apoyo." (Berenguer, p. 245)

Y es ahí, en la intencionalidad de cualquier obra literaria donde comienzan los problemas de la crítica contemporánea de Alma y vida.

El propio Galdós afirma en el prólogo de Alma y vida que la obra es simbólica, como veremos más adelante. Muchos críticos señalaron este carácter simbólico e intentaron explicarlo somo si se tratara de un jeroglífico que solucionar. Así, los dos protagonistas, Juan Pablo Cienfuegos y la Duquesa de Ruydíaz, pasaron a ser "la vida en toda su noble pureza" y "el ensueño y la gracia"4 respectivamente, es decir, la vida y el alma que dan título a la obra. Un ejemplo de otras interpretaciones pueden ser las siguientes opiniones: "del drama de Galdós (...) despréndese por cima de todo una verdad desconsoladora: que la vida es irreconciliable con el ensueño. La fuerza triunfa, pero el ideal se va" (Berenguer, p. 246). Hay quien va un poco más allá y llega a decir que "la duquesa anémica de Ruydíaz (...) quiere representar a España conmovida por los malos gobiernos como el dijéramos por Sagasta y Canalejas, aunque no es como el que trata de poner en solfa el señor Pérez Galdós" (Berenguer, p. 255). Uno de estos críticos, Luis López-Ballesteros, recoge las opiniones de algunos asistentes al estreno; para uno de ellos la obra representa "el principio de autoridad disolviéndose en el seno del pueblo", para otro "Galdós (...) personifica en la duquesa Laura la realeza, anémica, agonizante; y Laura, moribunda, se enamora del pueblo, comprende que en él está la vida"; una opinión más: "Juan Pablo Cienfuegos es la democracia, y vea usted, vea usted qué simpática se hace la majestad cuando la defiende contra los déspotas." (Berenguer, p. 252)

Estos son algunos de los comentarios que suscitó la obra entre sus espectadores, pero la opinión más difundida fue la de la oscuridad y dificultad que presentaba el símbolo encerrado en ella y que impidió al público "saber a ciencia cierta lo que se ha propuesto demostrar el autor." ${ }^{15}$ Este es el tema en el que nos vamos a centrar, pero antes quisiera mencionar simplemente otras quejas más pintorescas como las de aquellos que protestaron

4 Estas opiniones de Manuel Bueno (Ángel Berenguer, p. 250) fueron calificadas por Galdós en su prólogo como "el mejor punto de vista" (XII).

5 Esta opinión (Ángel Berenguer, p. 256) apareció también en otros dos periódicos, además de El Liberal Nuevo Mundo y El Diluvio. (Á. Berenguer, pp. 257, 258 y 249) 
por el trágico final, como si el autor tuviera la obligación de dar un "final feliz" al drama. ${ }^{6}$ Más adelante veremos cuál era la opinión de Galdós al respecto y el significado que quiso dar a ese final.

Galdós reaccionó rápidamente a todas estas críticas. En el prólogo que aparece en la edición Alma y vida del mismo año 1902, el autor fue pasando revista a todas las opiniones que, a su juicio, eran injustas con la obra.

Lo primero que pide Galdós a los críticos literarios de la prensa de su época es "que no sean desabridos y regañones con el que se proponga cambiar la tocata, aunque en ello no resulte totalmente afortunado"7, enlazado con el primer aspecto destacado por los críticos de la época que se vio más arriba: Galdós es un innovador, y así le ven sus contemporáneos, y así se ve él mismo. Por ello, Galdós lamenta que esos supuestos especialistas en literatura "vayan al teatro con la esperanza y el deseo de ver la repetición de lo que antes vieron" (VI).

Pero rápidamente pasa Galdós a ocuparse del tema fundamental en casi la totalidad de las críticas recibidas: el simbolismo de Alma y vida. Galdós quiere explicar el porqué de la utilización de dicha fórmula para su obra, y lo hace, como casi siempre, desde una perspectiva histórica: "el simbolismo tendencioso, que a muchos se les antoja extravagante, diré que nace como espontánea y peregrina flor en los días de mayor desaliento y confusión de los pueblos, y es producto de la tristeza, del desmayo de los espíritus ante el tremendo enigma de un porvenir cerrado por tenebrosos horizontes."(VII) No estamos, pues, y según las propias palabras del autor, ante una literatura dirigida. El autor no pretende imponer un punto de vista a su público, sino que éste debe llegar a una conclusión propia a partir del texto.

Esa interpretación personal debe ir unida a la experiencia colectiva que busca ser la obra literaria, especialmente el teatro, y así lo dice Galdós al referirse una vez más a la tan criticada cuestión de la oscuridad del símbolo:

No es condición del arte la claridad, sobre todo esta claridad de clave de acertijo que algunos quieren (...) También puede lograrse el ideal dejando ver formas vagas, bastante sugestivas para producir una emoción que no se fraccione, sino que se totalice en la masa de espectadores y unifique el sentimiento se todos. (XXI)

Toda obra tiene su intención y significado. Pero después de lo visto hasta aquí, debe quedar claro que no es la intención de este trabajo rebuscar una nueva interpretación del mentado símbolo de Alma y vida, sino proponer y aportar una serie de textos del autor que sirvan para complementar el significado de la obra y aclarar o al menos contextualizar aquellas opiniones e intenciones de Galdós que por lo simbólicas puedan aparecer confusas en Alma y vida.

La muerte de la duquesa de Ruydíaz impide la previsible boda entre los protagonistas.

7 Benito Pérez Galdós, Alma y vida. 1902, p.VI. Todas las citas de esta obra son de esta edición. Se indicará la página entre paréntesis en el texto; las citas del prólogo aparecen en números romanos. 
Una parte fundamental del prólogo está dedicada a explicar el origen de Alma y vida y su relación con ciertas circunstancias de la España de la época. Hemos visto algunas de las interpretaciones que la obra provocó en sus espectadores; veamos ahora lo que el propio autor dice acerca de los elementos a partir de los cuales surge el drama: "Nació Alma y vida del pensamiento malancólico de nuestro ocaso nacional"(XXII). Por tanto, y una vez más, estamos ante una reflexión acerca de la situación de España, una situación que Galdós define como de "parálisis patria"(XXVII). Pero siguiendo con la obra, un poco antes Galdós explica que su intención al escribir esta obra era

vaciar en los moldes dramáticos una abstracción, (...) la melancolía que invade y deprime el alma española de algún tiempo acá, posada sobre ella como una opaca pesadumbre (...) Veía yo como capital signo para expresar tal sentimiento el solemne acabar de la España heráldica llevándose su gloriosa leyenda y el histórico brillo de sus luces declinantes. (VII)

Efectivamente Galdós elige el siglo XVIII y un momento muy concreto de dicho siglo: "los años precursores de la Revolución francesa"(XXX). Nos encontramos así ante uno de los aspectos más interesantes de Alma y vida: el tiempo hisórico y su relación con el momento de producción de la obra.

Como acaba de explicar el autor, el tiempo escogido es el final del siglo XVIII, más concretamente 1780 . La proximidad de la Revolución francesa planea sobre el futuro del absolutismo, es decir, sobre el futuro de la clase dirigente hasta ese momento: la aristocracia. La nueva clase social que saldrá victoriosa de dicha revolución, la burguesía, encuentra ahora las condiciones históricas que al fin le permiten acceder al poder. España, una vez más, irá a remolque de Europa, pero el absolutismo está tocado y su fin próximo.

Algo más de un siglo después España termina definitivamente. En 1898 el imperio español, tan deslavazado desde hace tiempo, recibe su glope de gracia en una guerra desigual contra el nuevo imperio moderno. Como ya hemos visto, uno de los resortes que mueven a Galdós a escribir Alma y vida es la lucha contra el pesimismo que se había adueñado de la sociedad española a finales del siglo pasado y principios de éste. Este deseo de analizar la situación y los problemas de España hay que relacionarlo con el regeneracionismo. La necesidad de terminar con el caciquismo, la insinuación de una posible reforma agraria, son temas presentes en la obra. Pero, si bien los puntos de contacto son evidentes, también lo son las diferencias esenciales que separan a Galdós de las soluciones regeneracionistas. Lo veremos más adelante.

He hablado de pesimismo y es preciso recordar en este punto no sólo aquellas críticas ya mencionadas acerca del desgraciado final de la obra (la muerte de la duquesa), sino también y sobre todo, la respuesta que daba Galdós en su prólogo: "no hay final de drama más apropiado a la psicología nacional de estos tiempos". Pero seguidamente nos recuerda que el otro protagonista, Juan Pablo, no muere: "Harto simbolismo es dejarle vivo, con la particularidad, muy clara en toda la obra, de que representa la porción del país que no padece parálisis ni caquexia."(XXVIII) Hay, pues, una esperanza en la supervivencia de este personaje, que representa, al fin y al cabo, todo aquello que está realmente vivo en España a finales del XVIII, y quizá también a principios del XX. 
No hay pesimismo en la obra de Galdós, pero sí un análisis de un momento histórico muy concreto (el desastre del final del XIX), análisis que busca encontrar el origen de un problema que, como ve Galdós, hunde sus raíces en ese vuelco histórico que supuso la Revolución francesa y el fin del Antiguo Régimen. Para entender Alma y vida no hay que perder de vista la relación que el autor quiere establecer entre esos dos momentos históricos, ya que como dice Stanley Finkenthal "los personajes, en las obras del teatro [de Galdós], y no importa lo simbólicos que sean, viven en un mundo que es el reflejo teatral de momentos específicos de la historia de España"8, cosa que, por otra parte no es nueva. Lo interesante es que Galdós para dar cuenta del estado de España en 1902 retrocede hasta 1780 , ¿por qué?

Stanley Finkenthal, de nuevo, se acerca al verdadero problema de Alma y vida en cuanto a la relación entre 1780 y 1900, para él, lo que Galdós hace es utilizar episodios y hechos históricos en sus obras "para mostrar una vez más su visión del pasado y cómo ese mismo pasado continuaba influyendo y retrasando el pensamiento contemporáneo" (Finkenthal, p. 201).

Alma y vida presenta el momento en que se produce un cambio de poder en los dominios de la Duquesa de Ruydíaz. Monegro, el déspota que gobierna dichos estados en calidad de valido de la Duquesa, es derrocado en una supuesta revuelta popular. Digo supuesta, porque los que dirigen esa revuelta son los nobles, dominados también por Monegro y con ganas de sacudirse al molesto valido. La acción se distribuye de acuerdo con la siguiente estructura: el primer acto presenta el juicio al que es sometido el protagonista, Juan Pablo, al ser sorprendido la noche de San Juan dentro del castillo de la Duquesa; juicio muy interesante, porque en él se establecen dos puntos de vista: el del poder, que considera un criminal a este personaje, y el del propio Juan Pablo Cienfuegos que deja claro que su único crimen es precisamente su oposición en todos los aspectos (políticos, económicos y morales) al régimen opresor, venga de donde venga, como veremos.

El segundo acto parece detener la acción de la obra, ya que está ocupado por una representación teatral que los nobles habitantes del castillo preparan. Pero la intención de Galdós es clara al introducir este episodio:

Encariñado entonces, y de ello no me pesa, con la reconstrucción de una parte de la sociedad elegante de aquel tiempo y de sus afectados gustos literarios que anunciaban el ocaso de un mundo, pensé en la Pastorela, (...) esta clase de funciones señoriles, de una elegancia entre académica y suntuaria, que convertía en rosas el estiercol de las cabañas pastoriles, y en encajes las telarañas de los establos, signo del tiempo y de los delirios de una civilización refinada, que próxima á morir, suspiraba con los balidos de las blancas ovejitas. (XXX)

Mientras su mundo se desmorona, estos aristócratas se dedican a refugiarse en la ficción del mundo pastoril idealizado, tan alejado de esos pastores reales que brutalmente 
interrumpirán el ensayo reclamando justicia y pan (ya Cervantes, tan admirado por Galdós, había enfrentado a los protagonistas de las novelas pastoriles con los pastores reales a través de las realistas y sinceras palabras de Berganza en El coloquio de los perros ${ }^{9}$ ).

Los dos últimos actos están dedicados al triunfo de la revuelta contra Monegro, revuelta en la que está presente el pueblo, pero como simple acompañante, ya que como decía antes, esta "revolución" viene desde arriba, y quienes la dirigen son los nobles. Uno de estos nobles es Don Guillén, tío de la Duquesa Laura y adomado con las siguientes virtudes: (es Juan Pablo quien habla con don Guillén) "No olvido lo que me contásteis aquel día. Tan imperiosa es en vuestras entrañas la sed, mañana y tarde, que para remediaros habéis prevenido un depósito del tostadillo de la tierra en los distintos lugares que frecuentáis". (16-17)

Don Guillén es un borracho, pero no es la bebida su única obsesión; más adelante, comenta el propio don Guillén acerca de las doncellas de su sobrina: "Irene es linda... un poquillo pizpireta... Yo empecé á cortejarla, pero su coquetismo prolongó las resistencias más de lo que tolera mi carácter vivo, y me dediqué á Rosaura, que es más ingenua, más..." (19)

Vino y mujeres son las dos pasiones de don Guillén, y su odio hacia Monegro está basado en lo que podríamos denominar odio de clase. Lo que de verdad escuece a don Guillén no es la injusticia del régimen bajo el que vive, sino que un hombre de origen inferior, "ese insolente leguleyo"(20), sea quien decide lo que este noble venido a menos necesita para vivir. Así se lo cuenta el dolorido don Guillén a Juan Pablo:

para un hombre de alto nacimiento no hay pena más dolorosa que la humillación... Ese bárbaro [Monegro] satisface sus rencores plebeyos escarneciendo mi nobleza y cubriéndome de ignominia. Figúrate que ha limitado el socorro al plato diario en la mesa, y á una muda de ropa cada año, agregando para mi esparcimiento el tener bien surtidas mis cinco tabernillas, y dándome raciones muy tasadas de tabaco de segunda. (21)

Don Guillén vive de la caridad de su sobrina, en realidad, de la caridad de Monegro, que es quien dirige los estados de Ruydíaz, este noble es un parásito (y así lo denomina el propio Galdós en el prólogo, p. XXXIX) incapaz de solucionar su situación. Comparemos este personaje con las siguientes palabras que Galdós puso en boca de uno de los protagonistas de La razón de la sinrazón algunos años después:

la virtud verdadera y permanente consiste no sólo en el cumplimiento estricto de los deberes sociales, sino en la diligencia, en la actividad, en el trabajo constante, sin perder días, horas y minutos, en la creación de energías y en irradiarlas sobre los demás seres, contribuyendo a la florescencia de la vida humana. ${ }^{10}$

9 Miguel de Cervantes, Novelas Ejemplares. Madrid, Edaf 1986, p. 498.

10 Benito Pérez Galdós, La razón de la sinrazón; en Obras Completas VI, p. 389. 
Pero volvamos a don Guillén de Berlanga. Este hombre, incapaz de hacer algo útil con su propia vida, es uno de los instigadores de la revuelta que pretende derrocar al tirano Monegro. Ahora que conocemos bien a este personaje, la respuesta de Juan Pablo Cienfuegos cuando don Guillén le propone unirse a ellos en la lucha, es evidente: "No se cuente conmigo. No pretenden lós de Peñalba más que quitar un tirano para poner otro"(126). Idea que volverá a aparecer trágicamente al final cerrando la obra: "¿Qué habéis hecho, qué hemos hecho? Destruir una tiranía para levantar otra semejante. El mal se perpetúa..."(288)

Ese cambio de poder al que me refería más arriba no ha servido, pues, sino para cambiar algunos nombres, pero la organización de los estados de Ruydíaz seguirá siendo la misma, sin que en esencia cambie nada. Lo que parecía una revolución se ha quedado en una mera sustitución de un poderoso por otro. Las víctimas de aquella tiranía lo seguirán siendo bajo la nueva.

Si tenemos en cuenta que la obra transcurre pocos años antes de la Revolución francesa y que está escrita desde la perspectiva de 1902, no parece gratuito suponer que Galdós esté cuestionando ese cambio de poder histórico que supuso la primera revolución burguesa y que parece, en última instancia, haber llevado a España al Desastre del 98.

En relación con este tema, Isaac Rubio utiliza las palabras del propio Galdós para ejemplificar el pensamiento reaccionario y el atraso ideológico que, según Rubio, le llevó hacia el final de su vida a una deshistorización de los problemas y a una abstracción del sentido específico de toda coyuntura histórica (p. 174-175). Las palabras de Galdós son las siguientes: "... pues ahora resulta que la tiranía subsiste, sólo que los tiranos somos nosotros (...) la clase media, la burguesía..." ${ }^{11}$

Sin embargo, estas palabras parecen más bien un acto de lucidez por parte de Galdós a la hora de juzgar el significado de la burguesía en la organización del país. También hay que recordar que cada vez era más clara la idea de la existencia de dos dictaduras entre las que era forzoso elegir: la dictadura del proletariado y la dictadura de la burguesía ${ }^{12}$.

Parece clara, por tanto, la intención de Galdós de retroceder hasta 1780 para explicar la raiz de los problemas que sufre España en 1900. Otra cuestión es si Galdós vislumbra alguna solución.

Joaquín Casalduero, al dividir la obra de Galdós en etapas, decía que, en aquella que transcurre entre 1989 y 1907, periodo en el que se incluye Alma y vida, Galdós "no trata de estudiar la realidad histórica y de observar y explicar cómo Doña Perfecta mata a Pepe Rey, sino que le quiere dar un ideal a los españoles, y entonces Doña Perfecta es condenada a

11 Benito Pérez Galdós, Ensayos de crítica literaria. Edición de Laureano Bonet, Barcelona, Península 1990, p. 167.

12 Lenin, La Literatura y el Arte. Moscú, progreso 1976, p. 120. 
muerte: este es el significado de Casandra. ${ }^{13}$ ¿Cuál es ese posible ideal en el caso de Alma $y$ vida?

Antes de nada quisiera situar Alma y vida entre dos textos de Galdós que ejemplifican a la perfección la evolución idológica de su autor. El primero de ellos, fechado hacia 1895 , dice así:

Tras de una perturbación más o menos grande, según las localidades (se refiere a la celebración del $1^{0}$ de mayo), volverán las cosas al estado antiguo, y todo seguirá lo mismo, los capitalistas siempre explotando, los obreros trabajando siempre y viviendo al día (...) El remedio de la desigualdad no vendrá nunca, porque la desigualdad es irremediable, eterna y constitutiva. ${ }^{14}$

Diecisiete años después algo ha cambiado; Galdós parece vislumbrar una posibilidad que permite ser optimista. En 1912, en una entrevista, leemos las siguientes opiniones:

¿Qué preveo? Que todo seguirá lo mismo. Que volverá Maura y Canalejas, que los republicanos no podrán hacer lo que sinceramente desean, y así seguiremos viviendo hasta... Hasta que del campo socialista sobrevengan acontecimientos hondos, imprevistos, extraordinarios (...) ${ }_{i} \mathrm{El}$ socialismo! Por ahí es por donde llega la aurora. ${ }^{15}$

Alma y vida, situada a una distancia casi equidistante de estas dos opiniones, puede servir de puente entre ellas. El alma española que aparece en la obra está enferma, dominada su voluntad por un tirano, ansiosa de vida, pero encerrada en un cuerpo miserable. Tan grave es su estado que la alegría de un posible cambio real en la situación nacional acaba con ella. Un alma, en fin, y como dice Galdós en un texto de 1901, "esclava de lo que aquí llamamos caciquismo, tristísima repetición de los tiempos feudales y de las demasías de unos cuantos señores feuárbitros de los derechos y de los intereses de los ciudadanos". ${ }^{16}$

La causa de esta dolencia, de la que el Desastre del 98 no es sino una consecuencia más, es clara para Galdós: "nuestro enfermo [el pueblo español] reconoce con tristeza la esterilidad de sus esfuerzos, durante todo el pasado siglo, por darse un régimen político liberal a la europea". 17

Y si seguimos leyendo, encontraremos la elaboración de pensamientos que luego serán acciones en Alma y vida, como es la negativa de su protagonista a participar en una farsa que consiste en quitar un tirano para poner otro. Veamos como aparece explicando en "La España de hoy":

13 Joaquín Casalduero, Vida y obra de Galdós. Madrid, Gredos 1970, p. 187-188.

14 Benito Pérez Galdós, ibidem, p. 170.

15 Julio Rodríguez Puértolas, "Prólogo" a El caballero encantado, Benito Pérez Galdós.Madrid, Cátedra 19874, p. 17.

16 Benito Pérez Galdós, ibídem, p. 227.

17 Benito Pérez Galdós, ibídem, p. 227. 
Nuestros políticos agitaron la existencia nacional en el pasado siglo, sin fundar nada sólido, y todo lo hecho, en nombre de la democracia, contra el Gobierno personal, resultó de la misma hechura interna que lo que se quería destruir. Se variaban las apariencias y el nombre de las cosas; pero el alma permanecía la misma. ${ }^{18}$

O dicho en otros términos: no cambió la infraestructura del Antiguo Régimen y, por lo tanto, no se produjo una verdadera transformación de la sociedad española. En Alma y vida Galdós nos hace asistir al comienzo de la historia del siglo XIX, a aquellos cambios que no fueron tales y cuyas consecuencias sufre todavía España al comenzar el siglo XX, como observa el autor canario. Ángel del Río nos ofrece las siguientes palabras de Galdós: "Yo imagino, sin embargo, un tiempo en que cambiarán de parecer los que hoy empiezan a verme como un viejo maniático, obstinado en tomar en serio las luchas del siglo XIX y en ver por todas partes supervivencias del absolutismo." 19

La opinión del propio Ángel del Río sobre esta obra, según la cual, "Al morir la duquesa Laura - la España heráldica, la ideal virtud - el pueblo - la vida - se queda sin alma, y su triunfo, sin ideal superior que le inspire, ya sólo servirá para dar paso a nuevas tiranías" 20 , cae en un error al considerar que la lucha a la que asistimos es una lucha del pueblo, cuando, como hemos visto, el pueblo aquí no es más que un instrumento de los que desean hacerse con el poder.

El personaje que en Alma y vida se alza como portavoz de ese pueblo oprimido es Juan Pablo Cienfuegos. ¿Cuáles son sus características principales? Desde el principio de la obra aparece ante el espectador como un ejemplo de libertad y de individualidad. Su lucha contra el poder despótico de Monegro es una lucha personal que, en ocasiones, se une a la lucha de otros menos favorecidos que él. En el improvisado juicio que se organiza en el castillo de la duquesa donde ha sido descubierto Juan Pablo "se le acusa de haber incitado á la desobediencia y al descato á los pastores de las cabañas del Toral, despedidos por el señor Monegro"(49), a lo que el acusado responde: "no creo sedicioso hacerles comprender que la casa ducal, al despedirles, procedió contra fuero y contra el uso inmemorial (...) Yo les prediqué y repetí mil veces que no cedieran, que no se resignaran á ser tratados como bestias (50). Interesante respuesta, si tenemos en cuenta que se apoya en el pasado para defender a los pastores, en la organización patriarcal y casi feudal que se está descomponiendo con la llegada de nuevas relaciones de producción. ¿Es que no hay más solución que volver atrás? Esa es la respuesta de Galdós según Isaac Rubio (p. 187). Sin embargo, hay ciertas opiniones del protagonista que parecen alejarle del inmovilismo social o del deseo de aceptar las cosas como están:

"De modo que si no os dan justicia... - La tomo. No hay otro remedio. Dios no nos ha puesto en el mundo para que nos dejemos sacrificar estúpidamente.

Perezcamos defendiendo nuestro derecho, siendo jueces donde no los hay."(57)

ibídem

19 Ángel del Río, Estudios Galdosianos. Nueva York, Las Americas Publishing Co. 1969, p. 85. 
Si acudimos una vez más a otros textos de Galdós, quizá se puedan entender mejor algunos de estos aspectos de Alma y vida. En el mismo año de su estreno, 1902, Galdós publica uno de sus Episodios Nacionales, titulado Las tormentas del 48 , en el que podemos leer lo siguiente: "La riqueza pertenece a los trabajadores que la crean, la sostienen y aquilatan, y todo el que en sus manos ávidas la retenga, al amparo de un Estado despótico, detenta la propiedad, por no decir que la roba."21

Si volvemos al juicio que en Alma y vida se celebra contra Cienfuegos, leemos la siguiente defensa que hace ante la acusación de haber robado trigo, algarroba y vino, y que no deja de recordar al texto anterior:

Yo no tomé lo ajeno: no hice más que recobrar lo mío ¿lo queréis más concreto?

Lo mío recobré, que Vuestra Grandeza, no por sí, líbreme Dios de pensarlo, sino por mano del señor Monegro, me había quitado, valiéndose de servidores desleales, alquiladizos, que hacen inicuas trampas en la medición de frutos. (56)

Pero la denuncia puede transformarse en amenaza. Juan Pablo le dice a Monegro cuando por fin el tirano es derrocado: "No llaméis al rayo que ya vendrá... Y no temáis a los del cielo; temed á los de la tierra, á los que forja el hombre, cansado de la esclavitud, de la miseria, de tanta y tanta iniquidad." (264)

Un rayo que parece estar más cerca de estallar cuando leemos Casandra, escrita tres años más tarde: "Me declaro revolucionario callejero (...) Yo gritaré: ¡Abajo las fortalezas de injusticia y opresión, llámense leyes, tronos o altares! ¡Arriba nosotros, la turba, los desesperados, los desengañados!"22 Al llegar al último de los Episodios Nacionales, Cánovas, ese rayo se ha convertido en la única salida para no perecer como la protagonista de Alma y vida, de consunción, de anemia, de parálisis:

Alarmante es la palabra Revolución. Pero si no inventáis otra menos aterradora, no tendréis más remedio que usarla los que no queráis morir de la honda caquexia que invade el cansado cuerpo de tu Nación. Declaraos revolucionarios, díscolos si os parece mejor esta palabra, contumaces en la rebeldía. En la situación a que llegaréis andando los años, el ideal revoluicionario, la actitud indómita si queréis, constituirán el único símbolo de vida. Siga el lenguaje de los bobos llamando paz a lo que en realidad es consunción y acabamiento... Sed constantes en la protesta. ${ }^{23}$

Nada tiene que ver esta propuesta con las soluciones regeneracionistas como habíamos dicho anteriormente. Para que quede aún más claro no hay más que comparar estas palabras de Joaquín Costa con lo que se defiende en Alma y vida:

\footnotetext{
21 Benito Pérez Galdós, Las tormentas del 48; en Obras Completas II, p. 1510.

22 Benito Pérez Galdós, Casandra, en; Obras Completas VI, p. 170.

23

Benito Pérez Galdós, Cánovas,; en. Obras Completas III, p. 1410.
} 
Las revoluciones hechas desde el Poder no sólo son un homenaje y una satisfacción debida y tributada a la justicia: son además, el pararrayos para conjurar las revoluciones de las calles y de los campos. ${ }^{24}$

Juan Pablo Cienfuegos se negaba a participar en una revolución que, precisamente, venía desde arriba. Mientras tanto, esa escuálida alma española encarnada por la duquesa Laura muere consumida, incapaz de incorporarse a una vida nueva tantas veces anhelada: "Soñaba que Dios había dispuesto una transformación en mis estados; que mis vasallos vivían contentos; que tenían paz, bienestar, justicia... y yo... yo tenía salud... Mi endeble naturaleza también se transformaba."(253) Un anhelo de vida que se salta incluso normas y convencionalismos: cuando Cienfuegos es acusado de ser un mujeriego, Laura responde:

"Hace bien.

- ¡Pero la señora le disculpa!

- ¿Para qué se dejan ellas engañar tan á lo bobo?

-Pero los hombres no deben querer más que á una sola. -A una sola, ¿verdad señora?

-No, no: á muchas, á todas." (66-67)

Y en la conversación final entre Laura y Juan Pablo, ella le confiesa: "Lo mismo que tú haría yo si pudiese: burlar graciosamente las corrompidas autoridades, las estúpidas reglas y ficciones que nos encadenan."(261). Sin embargo, se trata de un alma incapaz de sobrevivir, y no hay que olvidar que la duquesa Laura se refugia en el mundo falso de la función teatral, ajena a la realidad que se desarrolla fuera de sus jardines. Un alma temerosa de todas las reacciones de su pueblo: al ver irrumpir a los pastores reales que vienen a reclamar justicia y comida, su primera pregunta es: "¿Nos harán daño?"(147). El mismo terror sentirá antes de morir $\mathrm{y}$, según parece, dejar sin alma al pueblo español.

Pero, ¿es trágico el final de Alma y vida? ¿Es cierto que muere lo mejor del alma española, dejando el pueblo sumido en la desesperanza?

En 1903 Galdós escribe un artículo titulado "Soñemos, alma, soñemos" que empieza así: "Aprendamos, con lento estudio,.a conocer lo que está muerto y lo que está vivo en el alma nuestra, en el alma española." 25 En Alma y vida muere Laura, que a pesar de su carácter ideal es, sin duda, infantil y arbitraria, dejándose llevar por los celos antes que por la justicia. El texto de "Soñemos, alma, soñemos" continúa de esta forma: "existe una capa viva, en ignición creciente, que es el ser de la Nación... Vida inicial, rudimentaria, pero con un poder de crecimiento que pasma."

Y ahí queda Juan Pablo Cienfuegos como representante de esta parte viva del alma española y no la enferma y desahuciada de la duquesa. Una vida nueva que mira hacia el futuro y que se niega a participar en una revuelta que empieza y termina en los de arriba.

24 Julio Rodríguez Puértolas, Carlos Blanco Aguinaga e Iris M. Zavala, Historia social de la literatura española II. Madrid, Castalia $1986^{2}$, p. 200; el subrayado es mío. 
En 1780, el comienzo de las luchas de la burguesía por hacerse con el poder dan paso a una nueva situación histórica. Para esos pastores hambrientos que aparecen de improviso en el jardín de Laura de la Cerda, duquesa de Ruydíaz, llegará un momento en que no se conformarán con la caridad y acabarán recuperando lo que en justicia les corresponde, como ya ha avisado Cienfuegos, un momento que en 1902 está ya peligrosamente cerca.

Povzetek

DUŠA IN ŽIVLJENJE, ZAČETEK ZGODOVINSKEGA PROPADA

Leta 1902 so v Madridu uprizorili gledališko delo Duša in življenje Benita Péreza Galdósa, ki je vzbudilo precej ostrih besed pri uradni kritiki, nekateri so celo govorili o popolnem polomu, čeprav je publika sprejela uprizoritev dokaj prisrčno, z globokim spoštovanjem do staroste španskega realizma. V odmevih na kritične poglede želi Galdós razložiti simboliko svojega dela, ki jo tudi tokrat, kot že mnogokrat prej, skuša osvetliti iz zgodovinskega zornega kota. Namen pričujočega prispevka je približati včasih tudi nekoliko zapleteno simboliko Duše in življenja s številnimi mnenji, ki jih je pisatelj izrekel $\mathrm{v}$ obrambo svojega gledališkega dela. 